\title{
Living together in a sexually exclusive relationship: an enduring, pervasive ideal?
}

\author{
Lampard, Richard
}

This is a post-peer-review, pre-copy edited version of an article published in Families, Relationships and Societies. The definitive publisher-authenticated version: Living together in a sexually exclusive relationship: an enduring, pervasive ideal?, Richard Lampard, Families, Relationships and Societies, is available online at: http://dx.doi.org/10.1332/204674314X14096686369849

\begin{abstract}
:
Recent demographic trends constitute movement away from forms of relationship behaviour central to hegemonic heterosexuality. The perceived legitimacy of cohabitation, relationship dissolution and same-sex partnerships has also increased. Has a further shift occurred, among people not living with partners, away from conventional coupledom as an ideal? Using data from the second National Survey of Sexual Attitudes and Lifestyles (NATSAL II), this article examines trends and patterns in the incidence of sexually exclusive co-residence as an ideal future lifestyle. While subscription to this 'traditional' ideal varies substantially with age and other salient factors, it nevertheless remains prevalent virtually throughout the 'single' population. Furthermore, there was no marked change across the 1990s in this ideal's popular appeal, highlighting its continuing influence as a 'meaning-constitutive tradition' (Gross, 2005). Relationship practices and ideals thus appear to have diverged, with the former changing more. However, as lifecourses unfold, people sometimes relinquish the traditional ideal, not infrequently favouring 'living apart together' instead.
\end{abstract}




\section{Introduction}

While a weakening of norms and a diversification of behaviour have occurred in Britain in relation to couple relationships, it is less clear to what extent monogamous co-residence, as an ideal, has lost its key role in structuring intimacy. Gross (2005) suggests that the detraditionalisation of intimacy in the US has involved a greater decline in the power of 'regulative traditions' than in the role of 'meaning-constitutive traditions'. Similarly, neither changes in behaviour nor changes in the forms of behaviour perceived as legitimate necessarily indicate a radical change in the ideals shaping (most) British people's behaviour. So, has co-resident coupledom become less important, not just as a practice but also as an ideal? This article assesses the extent to which sexually exclusive, co-resident relationships have persisted as an idealised future situation among people not living with a spouse or partner. It also examines variations in this ideal's incidence, since the extent to which it has remained pervasive within the subgroups most predisposed towards change has implications for future trends more generally. Particular attention is paid to 'Living-Apart-Together' $\left(\mathrm{LAT}^{1}\right)$, increasingly important as an alternative involving coupledom but not co-residence.

Changing ideas about coupledom certainly suggest that intimacy has, in some respects, been detraditionalised in Britain. While monogamous co-residence is still a central feature of 'hegemonic heterosexuality' (Hockey et al., 2007: 9-10), which also advocates lifelong marriages incorporating parenthood, 'everyday' ideas regarding heterosexuality have shifted, with cohabitation, voluntary childlessness and decisions to separate having greater legitimacy, and same-sex unions arguably normalised as a choice (Roseneil, 2000: 3.10; Hockey et al., 2007: 36; Budgeon, 2008: 303; Duncan and Phillips, 2008; Weeks, 2007: 198). 
Public views of single parenthood remain ambivalent, but solo-living is less stigmatised as a lifestyle (Macvarish, 2008: 34; Duncan and Phillips, 2008: 17).

Furthermore, patterns of behaviour have certainly changed. Britain's 'Second Demographic Transition' (Lesthaeghe, 2010) has seen later marriage, higher cohabitation and dissolution rates, and more single-person households, lone-parent families and (perhaps) LAT relationships (Roseneil, 2006: 4.4; Ermisch and Siedler, 2009). However, the extent to which the accepted existence of relationship-related diversity has been accompanied by changes in norms is disputed (Roseneil, 2000; Duncan and Smith, 2006; Weeks, 2007: 151). Jamieson (2004: 55) queries whether solo-living necessarily reflects coupledom declining as an ideal, and assessments of the implications of the growing importance of friendship networks for the normative role of exclusive sexual relationships vary markedly (Roseneil and Budgeon, 2004; Spencer and Pahl, 2006).

Both the extent to which the ideal of monogamous co-resident coupledom persists, and its patterns of prevalence across different parts of the British population, are currently unclear. This partly reflects the different methodological approaches underpinning the available empirical evidence. Quantitative evidence, while often nationally-representative, typically focuses on behaviour (see, however: Scott, 1998; Duncan and Phillips, 2008). Interpretations of quantitative behavioural change tend to infer its relationship to micro-level influences and subjective orientations: e.g. demographic changes relating to single-person households and LATs are sometimes interpreted, contentiously, as reflecting 'choice' (Weeks, 2007: 139; Budgeon, 2008: 301; Duncan and Smith 2006: 172). 
Conversely, while qualitative studies using non-random samples provide nuanced explorations of relationship orientations in the context of individuals' self-identities and construction of their social worlds, such studies often address generalisability issues inadequately when commenting on broad patterns and trends (Duncan and Phillips, 2010: 116). Unsurprisingly, given the nature of their evidence, authors' conclusions vary: between a suggested 'de-centering' of sexual couple relationships (Roseneil, 2000: 3.10-3.13), and the suggestion that aspects of (hetero)normative coupledom, including monogamy and coresidence, are exhibiting marked resilience (Hockey et al., 2007: 38).

Synthesising evidence across studies of relationship orientations where, since generalisability is not a primary objective, representativeness is questionable, and studies focusing on behaviour, necessitating speculation about orientations, poses an unresolvable methodological challenge. Hence nationally-representative survey data are used here to provide generalisable findings about orientations, specifically whether individuals have monogamous, co-resident coupledom as their ideal.

Turning from methodology to theoretical considerations, individualisation and an associated increase in reflexivity and agency underpin many accounts of changing relationship norms and practices (e.g. Giddens, 1992; Beck and Beck-Gernsheim, 1995; Bauman, 2003), and may have encouraged and legitimated solo-living, cohabitation and relationship dissolution (Kaufmann, 2008: 143-6; 193-4; Budgeon, 2008: 306). However, individualisation theorists have been criticised for inadequately-grounded assumptions of widespread, revolutionary change, which often ignore heterogeneity and continuities (Jamieson, 1998; Scott, 1998; Duncan and Smith, 2006). Furthermore, the 'transformation of intimacy' has not necessarily rendered coupledom undesirable (Giddens, 1992; Holmes 2004b: 255). Giddens' 'pure 
relationships', visible as an ideal in popular media discourses (Chambers, 2006: 45), in theory meet expectations of 'disclosing intimacy', emotional fulfilment and security, while providing autonomy and scope for identity development (Jamieson, 1998; Beck and BeckGernsheim, 1995).

Many young adults' relationship ideals do initially balance autonomy and intimacy (Budgeon, 2008: 314-319; Kaufmann, 2008: 176-8). Moreover, individuals sceptical about achieving this balance in practice may nevertheless retain, as an ideal, a relationship facilitating rather than constraining self-development (2008: 146-8). However, tension between norms of independence and autonomous identity and ideals of co-resident, couplebased intimacy can prompt delays in co-residence and increase 'serial monogamy' (2008: xviii; Weeks, 2007: 141). Thus changing practices, rather than indicating movement away from coupledom as an ideal, may instead indicate a divergence of relationship ideals and practices.

Given variations between social worlds and in exposure to discourses, increased agency may result in heterogeneous choices, with some resisting hegemonic heterosexuality, but many still accepting its constraints (Hockey et al., 2007: 183-4; Weeks, 2007: 126). While individualisation theorists apparently believe that living together in a sexually exclusive relationship is no longer a pervasive ideal, contemporary diversity and limited evidence have, to date, rendered speculative discussions regarding its current prevalence and the extent of change. 


\section{Diversity and change: Are there straightforward implications for}

the 'traditional' ideal?

Before presenting empirical analyses to address the afore-mentioned shortfall in evidence, this article evaluates literature relating to three forms of 'circumstantial evidence', used on occasions to support the suggestion that the extent and pervasiveness of the traditional ideal have declined. First, population subgroups are considered for which there is evidence of movement away from the traditional ideal. Such subgroups have sometimes been viewed as 'pioneers' of more universal change. The relevance of contemporary life-courses and of cultural and social contexts are then considered, since these aspects of contemporary society have often been seen as (increasingly) facilitating rejection of the traditional ideal. Finally, trends in behaviour are considered, since particular forms of behaviour have been interpreted as indicators of changing ideals.

Pioneers of 'new' ideals?

Lesbians and gay men have often been portrayed as pioneering pure relationships, plastic sexuality and friend-based personal communities (Giddens, 1992; Roseneil, 2000; Spencer and Pahl, 2006: 161-6). However, their relationship practices and perspectives are heterogeneous, highlighting both social continuities and change (Budgeon, 2008: 307; Weeks, 2007: 169, 184; Heaphy et al., 2012). Turning to other pioneering 'groups', sexual attitudes and lifestyles in London and 'inner cities' appear distinctive (Duncan and Smith, 2006; Weeks, 2007: 112); urban cultural diversity may facilitate diffusion of non-normative 
ideas (Roseneil, 2000: 4.1), and urban distinctiveness may also reflect migration's impact upon personal lives (Holmes, 2010: 147-8; Spencer and Pahl, 2006: 160).

Non-normative ideas and behaviour may also flourish among highly-educated professionals (Budgeon, 2008: 311-314), whose social circles may endorse transgressive ideas, advocating self-development more than coupledom (Jamieson, 2004: 54; Kaufmann, 2008: 39-40); the greater fluidity and (ideational) diversity of 'middle class' social networks (Chambers, 2006: 100-1; Spencer and Pahl, 2006: 168-70; Weeks, 2007: 175; Kaufmann, 2008: 155) may also be relevant. Paid work itself may encourage 'projects of self' which limit the scope for couple formation, and allow single women with appropriate social networks to develop robust, autonomous self-identities (2008: 82-91, 143-4; Trimberger, 2005: xvii-xviii). Equally, parent-child bonds can provide a strong sense of 'connectedness' (Weeks, 2007: 177-92); some lone mothers actively avoid co-residence, with childrearing as an identity source promoting LAT (Lampard and Peggs, 2007: 122; Duncan and Phillips, 2010: 115). However, focusing upon parenthood, employment or an active social life may alternatively reflect the perceived risks accompanying new partners, or serve to 'fill a gap' between partners (Lampard and Peggs, 2007: 124-31, 160-5).

A contemporary 'deferral' of adulthood (Hockey et al., 2007: 81) may reflect a prolonged phase of self-identity development which legitimates permissive, non-hegemonic practices, inconsistent with 'adult' heterosexuality's emphasis on co-resident intimacy (2007: 135-6; Trimberger, 2005: 258-9; Kaufmann, 2008: 193-4). Within this phase, friendship groups are often central, sometimes providing 'space for a counter-culture' against normative practices (2008: 22-40; Spencer and Pahl, 2006: 93-8; Heath, 2004). Characterising this phase as a transitory preliminary to coupledom is over-simplistic, as the living arrangements 
experienced can permanently affect lifestyle orientations (2004: 176; Trimberger, 2005: 248). Nevertheless, while wary of labelling young people's LATs as 'preliminary', Duncan and Phillips (2010: 112) suggest they often simply reflect a lack of readiness for co-residence.

Crucially, while the above-mentioned 'groups' provide evidence of contemporary diversity, it remains unclear how common the traditional ideal is within them, and whether their existence, or parallel influences, are impacting upon its pervasiveness elsewhere in the population.

Contextual influences: Change within life-courses

Lifestyle orientations sometimes evolve as life-courses progress. Focusing upon careers or personal interests sometimes leads to a happy, successful and autonomous life, into which couple-based intimacy no longer seems to fit; the advantages of single life can also raise expectations, restricting perceived options (Trimberger, 2005: 115-46; Simpson, 2009: 204-8; Kaufmann, 2008: 14, 149-50). Limited opportunities, and passivity regarding couple formation, can foster single lifestyles, with diminishing social pressures creating a 'legitimate space' for single identities (2008: 41-2, 156-70; Reynolds, 2008: 66-70). Reynolds (2008: 91105) finds growing reflexivity and self-perceived agency across single women's life-courses to be accompanied by a shift of orientation towards self-development. This may indicate that a coupledom ideal operating in a non-reflexive way, consistent with Bourdieu's concept of habitus, weakens in influence (Lampard and Peggs, 2007: 167).

Sometimes disruptions of the status quo cause traditional perspectives to be abandoned more abruptly (Weeks, 2007: 122; Trimberger, 2005: xv). Post-separation, independence and the 
(re)-establishment of self-identity can become an alternative ideal (Budgeon, 2008: 316-317; Simpson, 2009: 196). Individuals considering repartnering may also contrast, unfavourably, the available possibilities with imaginary, ideal partners (Lampard and Peggs, 2007: 111; Kaufmann, 2008: 107-8).

Contemporary life-courses certainly provide the impetus needed for some individuals to abandon the traditional ideal. However, the extent of the exodus thus prompted remains unclear; conversely, evolving life-courses may reinforce the traditional ideal.

\section{Contextual influences: Cultural context(s)}

In contemporary society, 'liberalising discourses' construct alternative lifestyles as positive choices (Hockey et al., 2007: 38), and the media provide fashionable images of singledom and friendship-based lifestyles, alongside negative images of conventional family life (Roseneil, 2000: 3.12; Kaufmann, 2008: xiii, 111-14, 148; Macvarish, 2008). However, notwithstanding such cultural portrayals and a greater diversity of practices, for many normative heterosexuality is still a 'given' (Weeks, 2007: 126), ultimately involving coresidence (Hockey et al., 2007: 25, 126). Furthermore, normative coupledom still often stigmatises contemporary alternatives (Kaufmann, 2008: 189). Negative representations of single people persist (Budgeon, 2008: 307), and the media continue to provide cultural resources idealising co-residence and supporting the 'centrality of romantic relationships' (Hockey et al., 2007: 95-108; Kaufmann, 2008: 156-70).

Awareness of alternatives to heteronormative practices has increased (Budgeon, 2008: 320; Roseneil, 2000: 3.12), but this may not lead to non-normative choices, since behaviour also 
reflects social worlds, individual concerns, and ideological considerations (Duncan and Smith, 2006: 171; Weeks, 2007: 171). More specifically, while radical feminists, queer theorists and libertarians reject sexual exclusivity (Jamieson, 2004: 35; Weeks, 2007: 151), their viewpoints, like those of pro-single social movements (Budgeon, 2008: 311), may not have a widespread impact; even within pertinent subgroups, radical ideas or practices are rarely universal (Duncan and Smith, 2006: 180; Kaufmann, 2008: 170-3; Weeks, 2007: 196; Jamieson, 2004: 52). Sexual exclusivity remains a resilient popular ideal, with nonmonogamy still stigmatised (2004: 37, 51; Hockey et al., 2007: 184); furthermore, nonmonogamous behaviour may not constitute a rejection of coupledom as a practice or ideal (Jamieson, 2004: 35-6).

Furthermore, the resilient cultural and personal importance of 'idealised partners', still found across diverse single lifestyles, bolsters coupledom as an ideal (Kaufmann, 2008: 105-14; Trimberger, 2005; Macvarish, 2008). However, idealised partners may undermine coupledom and promote being single as practices. Finding a partner who satisfies both dreams of romantic love and the expectation that a partnership will facilitate autonomy and identity development may seem increasingly unrealistic (Kaufmann, 2008: 57-9, 135-7; Reynolds, 2008: 69-70), and 'holding out' for one can justify a work and friend-orientated lifestyle (2008: 89). Moreover, the romantic notion that such partners 'appear from nowhere' encourages passivity (Kaufmann, 2008: 127; Simpson, 2009: 204).

To summarise, the contemporary cultural context can certainly provide discursive resources that, aided by individualisation, legitimise rejection of the traditional ideal, facilitate diverse practices, and allow the construction of positive single identities (Budgeon, 2008: 311; Reynolds, 2008: 76-8). However, social networks and other contextual influences affect how 
such resources, along with resources supporting the traditional ideal, are utilised (2008: 403). Hence the traditional ideal, while not universal, may nevertheless remain pervasive, coexisting with alternative, socially-sanctioned practices.

\section{Contextual influences: Social worlds and (forms of) reflexivity}

Social networks can provide role models for solo-living and diverse sexual practices (Roseneil, 2000: 3.11; Kaufmann, 2008: 143-5), or for normative coupledom (2008: 32-4, 956). However, individualism, particular orientations, and 'new' relationship forms vary in prevalence between social networks (and localities), and 'local norms' may over-ride 'societal norms' (Duncan and Smith, 2006: 169-70; Weeks, 2007: 112-13, 170-8); in 'social worlds' with low levels of diversity and individualisation, the influence of examples of nonnormative orientations and practices may be restricted (2007: 175; Duncan and Smith, 2006: 180).

Crucial to continuity or change in relationship ideals and practices is how individuals exercise reflexivity and agency in the contexts of discourses, norms and their specific social worlds. Contributions which situate reflexivity and agency 'as ... practice[s] of actual human beings', located in particular social worlds (Holmes, 2010: 141), such as Archer's typology of forms of reflexivity (Archer, 2003), highlight the heterogeneous impact of social change. Archer's 'communicative reflexives', with interpersonal senses of identity and life-histories characterised by 'contextual continuity', typically replicate 'standard' behaviour within their social worlds, including normative co-residence (2003: 235; Holmes, 2004b: 255-6). 'Autonomous reflexives', who tend to 'dovetail' relationships with a primary focus on performative achievement (Archer, 2003: 219), are unlikely to seek 'disclosing intimacy' or 
adopt a radical/political perspective on coupledom. Hence any tensions between their selfidentities and coupledom are likely to be practical. 'Meta-reflexives', who are more likely to critique relationship norms, may nevertheless seek to reinforce their self-identities via partners sharing their primary concerns (2003: 280).

However, some 'meta-reflexives' prefer friendship networks to heteronormative coupledom, and some 'autonomous reflexives' engage in 'distance relationships' to sustain work-related achievement (Holmes, 2004a: 197). Variations in reflexivity certainly resonate with the diversity of contemporary ideals and practices (Holmes, 2010: 147-8); nevertheless, the forms of reflexivity Archer identified as prevalent do not guarantee any marked decline in the traditional ideal's pervasiveness.

\section{Changing behaviour, changing ideals?}

This sub-section considers the challenge to the traditional ideal arguably posed by LAT, staying single, and friendship networks. LATs sometimes constitute an alternative lifestyle, challenging norms of co-residence, exclusivity and the centrality of partners, and facilitating a balance between intimacy and autonomy or existing commitments (Roseneil, 2006; Kaufmann, 2008: 176-8). However, LATs are heterogeneous (Roseneil, 2006): Do the participants want to live apart? Would living together be impractical? Are they heading for co-residence?. At younger ages, LATs often constitute a traditional, short-term preference (Duncan and Phillips, 2010); among the formerly partnered, LAT is often preferred initially, with co-residence neither anticipated nor ruled out (Lampard and Peggs, 2007: 147). 
Arguably, the growing visibility of LATs neither indicates increased choice nor reduced commitment; participants typically have less traditional views of marriage than married people, but not pioneering, radical attitudes (Duncan and Phillips, 2010: 113, 132). Many LATs reflect employment or housing-related constraints rather than preferences (2010: 11320; Holmes, 2004b: 254). Formerly partnered people's non-resident relationships are sometimes pragmatic compromises, co-existing with more traditional ideals (Lampard and Peggs, 2007: 133-5, 146; Kaufmann, 2008: 173-4).

Turning to single people, their increased prevalence has arguably 'denaturalized' coresidence (Budgeon, 2008: 310). However, they do not uniformly threaten co-residence as an ideal; many accept the coupledom norm, viewing their lives as lacking something (Simpson, 2009: 199; Kaufmann, 2008: 110). Some, actively seeking co-residential partners, remain single because of high expectations (2008: 105-7). Others would contemplate co-residence if somebody 'good enough' came along (2008: 67-8; Simpson, 2009: 204). Solo-living can reflect passivity as much as agency: e.g. among women influenced by romantic discourses and notions of fate (Lampard and Peggs 2007: 123-32; Macvarish, 2008: 20). Those who are single through passivity or limited opportunities sometimes struggle to experience single life positively; many with positive, independent self-identities do not prefer singleness to coupledom (Simpson 2009: 233; Kaufmann, 2008: 147-71).

Nevertheless, tensions with self-development, performative achievement, freedom, or friendship networks lead some single people to critique the coupledom ideal (Budgeon, 2008: 313-16), although sometimes alongside dreams of ideal partners (Kaufmann, 2008: 68). A distinctive minority intentionally construct their lives around extensive social networks (2008: 95-103, 153-5; Spencer and Pahl, 2006: 198), undermining the assumption that 
coupledom is an universal aspiration (Simpson, 2009: 140-6; Budgeon, 2008: 319). However, while friendship networks as an identity source arguably undermine the value of exclusive sexual relationships (Roseneil and Budgeon, 2004: 146-50), 'friend-based' personal communities are not necessarily radical in nature or consequences (Weeks, 2007: 179-83). Even where friendships are crucial to self-identity, individuals may covet partnerships for their (allegedly) unique qualities, not always seeing friendships as reliable, legitimate longterm sources of support (Spencer and Pahl, 2006: 64, 171-2; Chambers, 2006: 91, 167-8; Macvarish, 2008: 12-21).

Friendship networks appear particularly important within some population subgroups (including those 'pioneering' new ideals): members of LATs, partly reflecting age (Roseneil, 2006; Duncan and Phillips, 2010: 126-30); young, highly-educated migrants/urban residents (Spencer and Pahl, 2006: 160; Budgeon, 2008: 311); individuals post-separation (2008: 318); 'new single women' (Trimberger, 2005: xviii); and stigmatised or marginal groups (Chambers, 2006: 106-8; Weeks, 2007: 179-81). However, it remains unclear how generally friendships now constitute a viable, preferred source of intimacy and identity.

Like the other highlighted forms of behaviour, friendship networks are heterogeneous, sometimes challenging the traditional ideal, but often not. How much the prevalence of any of these forms of behaviour should be interpreted as querying the traditional ideal's enduring, pervasive nature is consequently unclear.

(In)conclusive evidence of revolutionary change? 
The evolution of life-courses and of the cultural context have undoubtedly caused or facilitated changes in relationship behaviour and/or orientations, particularly within some population sub-groups, leading to considerable diversity. However, this neither implies that the traditional ideal has become rare in these sub-groups nor implies that it is withering across the population more generally.

\section{Data and measures}

This article analyses the second National Survey of Sexual Attitudes and Lifestyles, (NATSAL II), which sampled 12,110 individuals aged 16-44 during the period 1999-2001 (Erens et al., 2003; NatCen, 2005)루 ; comparisons are also made with the 1990 survey (Field et al., 1995). The dependent variable, focusing on sexually exclusive co-residence as an ideal lifestyle $^{3}$, arises from one of two, linked questions regarding ideal sexual lifestyles 'now' and 'in five years' time'. ${ }^{4,5}$ The second question is used, because it allowed respondents to set aside short-term factors affecting their ideals, specifying a substantial period during which they could envisage moving through any stages preliminary to their ideal situations. NATSAL II also collected extensive data on characteristics potentially relevant to relationship ideals, hence the analyses include independent variables corresponding to various themes discussed earlier, including 'pioneering' subgroups and individuals' lifehistories. Attitudinal measures allowed diverse perspectives on intimacy and sexuality to be considered.

More specifically, NATSAL II provided detailed histories of sexual behaviour and coresidence, and recorded the sex(es) to which respondents had felt sexually attracted. Measures also included whether respondents had given birth to (or fathered) children. 
Respondents were also asked how important various things, including having children, were to a successful marriage or long-term relationship; their views regarding the importance of fidelity, a happy sexual relationship, mutual respect, and sharing household chores arguably indicate how much they endorsed (aspects of) 'pure relationships'. Further attitudinal measures included views on pre-marital sex, 'one-night stands' and homosexual behaviour, views on infidelity within particular forms of couple relationship, and views on abortion. ${ }^{6}$ NATSAL II recorded other potentially relevant characteristics, including: own/parental social class, qualifications, employment status, ethnicity, religiosity, region, geographical mobility, tenure, and type of dwelling. ${ }^{7}$

Categories were often aggregated to render variables more concise, preserving salient or statistically significant differences. Within the multivariate analyses, age categories allow for non-linearity, and an age/sex interaction term allows for gendered life-course variations.

\section{Trends and age differences}

Table 1 compares between NATSAL II and NATSAL I the distributions of current relationship types or, for those without a co-resident partner, ideal relationship situations in five years' time, documenting change from 1990 to $1999-2001 .^{8}$ To ensure comparability, findings are restricted to NATSAL II's age range, 16-44, and are standardised using its age structure, as the respondents' age distributions differ (Erens et al., 2003).

[Table_1_here] 
The most striking change (equivalent to 12.7 per cent of cases) is the growth in cohabitation as current practice or ideal, mirroring a decline in marriage as practice or ideal (12.8 per cent). A decline in current co-residence (3.0 per cent) is largely counter-balanced by a growth in sexually exclusive co-residence as an ideal ( 2.2 per cent), reflecting a shift to later first cohabitation or marriage. Crucially, the Table 1 results do not indicate any substantial change between the surveys in co-resident, sexually exclusive relationships as an ideal for the future, combined with co-residence as a current practice. The small decline that is evident ( 0.8 per cent $^{9}$ ) may reflect a shift towards LAT as an ideal (1.3 per cent). The heterogeneity of LATs (Roseneil, 2006) is relevant here: some of this shift is within the youngest age group (see Table 2), suggesting that co-residence may be being deferred as an ideal, not just as a practice, but most of the growth in LAT as an ideal relates to people aged 30 plus. ${ }^{10}$

[Table_2_here]

The simplified category range in Table 2 highlights how the balance varies, according to age, between current co-residence combined with exclusive co-residence as an ideal, LAT as an ideal, and having more than one (sexual) partner as an ideal. At age 25-29, very few NATSAL II respondents fall outside these possibilities, with 93.6 per cent either living with a partner or favouring sexually exclusive co-residence. This suggests that, for most people, friendship networks are viewed at most as temporarily 'substituting' for coupledom (Kaufmann, 2008: 34-38; Spencer and Pahl, 2006: 93).

The LAT ideal is least prevalent (3.0 per cent) in the $25-29$ age range, which may be the 'turning point' for the balance of importance as ideals of 'not ready for co-residence' LATs and other types (Duncan and Phillips, 2010; Roseneil, 2006). Unlike the LAT and 'residual' 
categories, the category corresponding to favouring multi-partner lifestyles continues to get smaller past age 30, for both sexes. Analyses of formerly-partnered NATSAL I respondents suggest that favouring LAT or 'celibacy' becomes increasingly common at ages beyond NATSAL II's ceiling of 44; cumulative experiences may promote reflexivity, stimulating disengagement from the traditional ideal (Lampard and Peggs, 2007: 104-5).

\section{Sexually exclusive co-residence as an ideal for the future: A multivariate analysis}

This section focuses upon whether 'partner-less' people view a sexually exclusive, coresident relationship as their ideal situation in five years' time. It examines determinants of variation in the odds of having this ideal, using results from a multivariate analysis applying binary logistic regression to the sub-sample of 5,908 NATSAL II respondents without co-

resident partners. ${ }^{11}$ Supplementary binary logistic regressions compared this ideal to LAT as an ideal, and to a multi-partner lifestyle as an ideal, helping establish whether significant overall effects relate to these specific alternatives. Table 3 documents the magnitude and statistical significance of the explanatory variables' effects, which take the form of odds ratios; significant effects within the supplementary analyses are also indicated.

[Table_3_here]

Taken together, the results corresponding to age, sex and their interaction are consistent with the likelihood of having a co-resident, sexually exclusive relationship as one's ideal future relationship situation being relatively low at 16-17, rising markedly for women at 18-19 and men at 20-24, peaking at 25-29, and declining thereafter, somewhat more markedly for 
women. This matches the suggestions that, for most people, this ideal is adopted during young adulthood as individuals become 'ready' for co-residence (Duncan and Phillips, 2010: 112), but that the shift towards this ideal eventually ceases, with 'partner-less' people subsequently increasingly orientated towards alternatives. The latter could reflect people becoming habituated to single lifestyles (Heath, 2004; Trimberger, 2005), or be a selection effect, reflecting compositional changes to the 'partner-less' arising from relationship formation and dissolution.

A low likelihood of subscribing to the traditional ideal for individuals yet to have a sexual partner may indicate less frequent anticipation of being 'ready' for an exclusive, co-resident relationship in five years' time, ${ }^{12}$ as may the low likelihood for individuals whose last sexual partner was 'casual', although this might also reflect non-traditional lifestyles. Limited (inconclusive) evidence hinted that individuals whose last sexual partner was a second or later spouse disproportionately favoured LAT, consistent with the repartnering literature (Lampard and Peggs, 2007). However, individuals who had cohabited with their last sexual partner markedly less often favoured LAT, possibly indicating 'readiness' for co-residence, or current, 'involuntary’ LATs with former cohabiting partners (Duncan and Phillips, 2010).

Unsurprisingly, the results for individuals reporting three or more sexual partners within the last year, and especially eight plus, indicate a less frequent preference for exclusive, coresident relationships in five years' time. This may reflect a subgroup favouring long-term non-traditional lifestyles, as may the markedly lower prevalence of the traditional ideal among those reporting same-sex sexual attraction, who nevertheless mostly reported such an ideal, qualifying this group's role as 'pioneers', as does some of the literature (Weeks, 2007; Heaphy et al., 2012). 
Furthermore, graduates disproportionally favoured the traditional ideal, undermining the suggestion that they lean towards non-normative ideas (Budgeon, 2008; Kaufmann, 2008). 'Careers' possibly operate as a barrier to co-resident relationships, increasing the proportion of graduates and non-manual workers who are 'frustrated traditionalists'. However, current students were less likely to have sexually exclusive co-residence as their future ideal, perhaps anticipating that careers would still be taking priority, and people from 'mid-range' class backgrounds disproportionately favoured the traditional ideal, perhaps reflecting less exposure to undermining influences.

Some non-employed categories exhibited a relatively low incidence of the traditional ideal. People receiving unemployment benefits, or with long-term health problems, or looking after homes and families, may have more pressing concerns, making them less likely to anticipate wanting a co-resident partner in five years' time. Seeing an adequate income as very important to marriage was also associated with a lower likelihood of favouring the traditional ideal. This may reflect an anticipated financial inability to meet traditional expectations regarding creating a family home, rather than constituting a critique of co-resident coupledom.

Conversely, the results indicate that childless people who saw children as very important to a marriage or long-term relationship were disproportionally orientated towards co-residence (rather than LAT) ${ }^{13}$. Not having a child appears to push some individuals towards the traditional ideal more than having children pushes lone parents away from it. An inclination among the latter to avoid normative lifestyles in practice (Roseneil, 2006: 9.3) may co-exist with an imagined ideal partner/co-parent (Kaufmann, 2008: 64-8, 142, 173-7). 
People who had not always lived locally showed a preference for co-residence rather than LAT. Rather than encouraging alternative lifestyles (Holmes, 2010: 147-8), geographical mobility may instead, by hindering couple formation or co-residence, generate 'frustrated traditionalists'. Regional differences may have a similar explanation: achieving a preferred co-residential lifestyle may be easier economically in Britain's North and West, leading to proportionally more 'frustrated traditionalists' in its East and South. However, London's distinctiveness, reflecting a more frequent multiple-partner lifestyle orientation, suggests that geographical differences also reflect variations in different lifestyles' prevalence or cultural acceptability, echoing Roseneil's suggested link between urban cultural diversity and the diffusion of non-normative ideas (Roseneil 2000: 4.1). ${ }^{14}$

The less important religion was to individuals, the less likely their ideal was to be sexually exclusive co-residence. ${ }^{15}$ Turning more specifically to attitudes, the minority strongly querying fidelity's importance or infidelity being wrong unsurprisingly showed less adherence to the traditional ideal, especially relative to ideals involving multiple partners. The existence of a subgroup questioning monogamy's importance, and less frequently having sexually exclusive co-residence as their ideal for the future, arguably corroborates Giddens' suggested increase in freedom of expression regarding intimacy. The results corresponding to views on one-night stands and the importance of sex within marriage also suggest that a subgroup within the population deviates, in terms of both attitudes and relationship ideals, from what is still normative for the majority. ${ }^{16}$

However, only a few percent of the sample are clear-cut members of any such 'pioneering' subgroup. This, together with the absence of much change in the distribution of relationship 
ideals during the $20^{\text {th }}$ Century's last decade, paints a rather static picture, querying the existence of a revolution in relationship orientations, or even substantial, ongoing evolution. Furthermore, any suggestion that the minority of partner-less people who do not endorse the traditional ideal homogeneously reflects a gay and lesbian-led shift towards 'plastic sexuality' is undermined by the greater tendency of those viewing homosexual relations as always wrong to favour multiple-partner lifestyles. Rather than reflecting contemporary freedom of sexual expression, this may reflect a traditional masculinity that is both homophobic and celebrates promiscuity.

Moreover, the orientations of some of this heterogeneous minority may reflect the ongoing absence of 'democracy' and equality within many heterosexual couple relationships; specifically, the result corresponding to the importance of sharing household chores suggests that women who particularly value egalitarian relationships may be more sceptical about the likelihood of sexually exclusive, co-resident relationships being 'democratic' (Giddens, 1992). ${ }^{17}$ Less adherence to the traditional ideal among individuals only seeing mutual respect within relationships as 'quite' important also resonates more with the suggested shallowness of some contemporary relationship bonds (Bauman, 2003) than with Giddens' optimistic view of contemporary intimacy.

Overall, the findings confirm that the likelihood of having sexually exclusive co-residence as an ideal varies substantially between different elements of the population. ${ }^{18}$ However, bivariate analyses showed that the proportion endorsing the traditional ideal lies in the range 50-90 per cent for nearly all the categories of all the explanatory variables, the exceptions being a few minor categories within the ethnic, tenure, and importance of marital fidelity measures. In addition, only 13 per cent of the model's predicted probabilities of having 
sexually exclusive co-residence as an ideal fall below 0.5 , and only 1 per cent below 0.25 . So, an individual's combination of characteristics would seldom make the 'best guess' that they did not subscribe to the traditional ideal, and very rarely make it reasonably safe to assume this. Conversely, 15 per cent of the predicted probabilities are above 0.9; furthermore, in the age range $25-29$, the proportions below 0.5 and above 0.9 are 2 per cent and 37 per cent. So there is a substantial minority of individuals whom it would be reasonably safe to assume $d o$ subscribe to the traditional ideal, especially in the 25-29 age range, which contains very few individuals for whom the 'best guess' would be that they did not subscribe to it.

To summarise, this article has not identified any important subgroups within the "partnerless' population aged 16-44 which could, on the basis of most people in them not subscribing to the traditional ideal, be interpreted as 'championing a new outlook' on coupledom. Furthermore, focusing specifically on people aged 25-29, the logistic regression model only identifies a very small proportion of individuals whom it predicts as not subscribing to the normative ideal of sexually exclusive, co-resident coupledom, but identifies a substantial minority as unlikely to deviate from it.

\section{Concluding discussion}

Later couple formation and a shift towards 'serial monogamy' have 'decentred' coupledom somewhat as a practice, but this article suggests that the 'traditional' relationship ideal of sexually exclusive co-residence, while not universal and apparently losing salience with age, retains a stable, widespread influence. Individuals not subscribing to the traditional ideal constitute a heterogeneous minority, with diverse ideas about sexual behaviour and relationships that may in different instances resonate with feminist, queer theoretical, 
Giddensian, libertarian, or (some) 'traditional masculine' perspectives. However, while this minority mirrors contemporary lifestyle diversity, highlighting the decline of sexually exclusive co-residence as a regulative tradition (Gross, 2005), it is not apparently growing substantially, perhaps restricted by the resilience of certain normative ideas, e.g. regarding fidelity and parenting. Furthermore, people whose religious or familistic perspectives underpin the traditional ideal constitute another ongoing minority.

Crucially, this article failed to identify any important population subgroups wherein the empirical norm was not to subscribe to the traditional ideal, hence the 'pioneers' of new ideals might best be viewed as belonging to, rather than being, particular groups (Simpson, 2009: 210-12). Furthermore, contra the views of individualisation theorists, the traditional ideal remains pervasive: both overall and also in the sense of being commonplace within a diverse range of social groups.

Sexually exclusive co-residence thus apparently retains considerable influence as a meaningconstitutive tradition (Gross, 2005). A lack of tension between this traditional ideal and key contemporary forms of reflexivity (Archer, 2003) may account for reflexivity-related change not having eroded its pervasiveness substantially. Furthermore, at least in the early decades of adulthood, relationship ideals may be less often determined by reflexivity than by Bourdiesian habitus (i.e. cultural influences embedded via socialisation), or by attention to other concerns. While non-resident relationships initially appear normative among young adults, the people in their late twenties examined here typically appeared 'ready' to subscribe to the traditional ideal. The influences underpinning this outcome may include: a perception of what is culturally normative, pressure to replicate 'conventional' behaviour in social worlds where it prevails (Duncan and Smith, 2006), and the evolution of personal 
circumstances as life-courses unfold, both regarding relationships and more generally. Lauer and Yodanis (2010) suggest such factors and processes explain the persistence of the decision to marry in the US, concluding that behavioural change and lifestyle diversification do not necessarily constitute a 'deinstitutionalization' of marriage.

Nevertheless, some life-courses lead individuals away from subscription to normative coupledom (Trimberger, 2005: xiii). Competing concerns may increase in importance; 'jolts' resulting from discontinuities, combined with greater reflexivity, may undermine the influence of habitus; social and cultural pressures may decline as individuals traverse lifecourse territory rendered uncharted by the new era of 'serial monogamy', in which even meaning-constitutive traditions may be less influential. In this context, theoretical ideas integrating greater freedom of choice and increased attention to 'risks' (Beck and BeckGernsheim, 1995) appear particularly pertinent, and 'Living-Apart-Together', as a means of balancing independence and intimacy or as a risk-management tool, seems increasingly important as an alternative to normative coupledom (Lampard and Peggs, 2007: 163-7, 2112).

Overall, the persistence and prevalence of the traditional ideal, as shown here, seem consistent with relationship ideals and relationship practices having diverged. This may reflect the decline of sexually exclusive co-residence as a regulative tradition, together with the impact on practices of various other influences, including the rise of performative achievement as a competing concern, greater structural constraints (spawning 'frustrated traditionalists'), unrealistic expectations generated by images of ideal partners or the 'Shangri-La' of pure relationships (Kaufmann, 2008; Giddens, 1992), and a weakening link between coupledom as a preference and as a central, active objective. This weakening may 
reflect passivity induced by 'ambivalent ... cultural and social descriptions of family life', or by a lack of frameworks facilitating relationship formation, or by a sense that love should occur without 'rational action' (Macvarish, 2008: 27). Diverse influences on relationshiprelated behaviour may have rendered it a poor indicator of relationship orientations; social change may have affected practices more than ideals. 


\section{Notes}

1 'LAT' denotes 'Living-Apart-Together' as a behaviour; 'LATs' denotes particular 'Living-Apart-Together' relationships.

2 Multi-stage random sampling induced disproportionalities, necessitating weighting. 35 individuals of unknown marital status are omitted.

3 The focus is thus on ideal relationships rather than ideal partners.

4 Respondents selected a letter corresponding to one of eight showcard options (see Table 1); those reporting no ideal, an unlisted ideal, or answering 'don't know', constitute a ninth category.

5 Unfortunately the questions were not repeated in the later, NATSAL III survey.

6 The 'happy sexual relationship' measure and the measures for views on pre-marital sex and infidelity in cohabiting relationships lacked statistical significance controlling for other variables, as did the second sex-specific measure of attitudes to homosexual relations.

7 Other variables omitted without significantly worsening model fit include: marital status; heterosexual/homosexual 'experiences'; religious denomination; country of birth; childhood family structure.

8 For brief discussions manipulating some of these data differently, see: Erens et al. (2003: 14); Duncan and Phillips (2010: 121). While potentially 'living' the traditional ideal, individuals with co-resident partners did not always have it as their future ideal: $5.3 \%$ favoured non-exclusivity, with $3.9 \%$ not favouring co-residence, perhaps reflecting the specifics of their current partnerships.

9 Non-significant $(p=0.227)$.

10 The age $30+$ change is proportionally smaller, but the category much larger. 
11 Again applying weights.

12 An interaction check suggested a stronger effect for women.

13 Note the significant interaction term.

14 Echoing work and fertility histories, housing histories/situations appear linked to relationship orientations.

15 Only a few, small ethnic categories exhibited statistically significant variation.

16 An interaction check indicated a stronger effect for men.

17 An interaction check identified this as gender-specific. The abortion-related effect may reflect similar scepticism, if 'not at all wrong' proxies feminist views.

18 There was little evidence of further interaction effects. 


\section{Acknowledgements}

Data obtained via the UK Data Archive were collected by NatCen. Like the depositor, copyright holders and research funders, they bear no responsibility for these analyses/interpretations. I would like to thank everyone who provided constructive and helpful feedback on earlier versions of this article. 


\section{References}

Archer, M.S. (2003) Structure, agency and the internal conversation, Cambridge: Cambridge UP.

Bauman, Z. (2003) Liquid love, Cambridge: Polity.

Beck, U. and Beck-Gernsheim, E. (1995) The normal chaos of love, Cambridge: Polity.

Budgeon, S. (2008) 'Couple culture and the production of singleness', Sexualities, 11(3): $301-25$.

Chambers, D. (2006) New social ties, Basingstoke: Palgrave.

Duncan, S. and Phillips, M. (2008) 'New families? Tradition and change in modern relationships', in A. Park, J. Curtice, K. Thomson, M. Phillips, M. Johnson, and E. Clery (eds) British Social Attitudes: the $24^{\text {th }}$ report, London: Sage, 1-28.

Duncan, S. and Phillips, M. (2010) 'People who live apart together (LATs) - how different are they?', Sociological Review, 58(1): 112-34.

Duncan, S. and Smith, D. (2006) 'Individualisation versus the geography of 'new' families', $C 21^{\text {st }}$ Society: Journal of the Academy of the Social Sciences, 1(2): 167-90.

Erens, B., McManus, S., Prescott, A., and Field, J. (2003) National Survey of Sexual Attitudes and Lifestyles II: Reference tables and summary report, London: NatCen/UCL/LSHTM.

Ermisch, J. and Siedler, T. (2009) 'Living apart together', in M. Brynin and J. Ermisch (eds) Changing relationships, London: Routledge, 29-43.

Field, J., Johnson, A., Wadsworth, J. and Wellings, K. (1995) National Survey of Sexual Attitudes and Lifestyles, 1990 [computer file], Colchester: UK Data Archive. [SN3434].

Giddens, A. (1992) The transformation of intimacy, Cambridge: Polity.

Gross, N. (2005) 'The detraditionalization of intimacy reconsidered', Sociological Theory, 23(3): 287-311. 
Heaphy, B., Smart, C. and Einarsdottir, A. (2012) Same sex marriage, London: Palgrave Macmillan.

Heath, S. (2004) 'Shared households, quasi-communes and neo-tribes', Current Sociology, 52(2): 161-79.

Hockey, J., Meah, A. and Robinson, V. (2007) Mundane heterosexualities: From theory to practices, Basingstoke: Palgrave.

Holmes, M. (2004a) 'An equal distance? Individualisation, gender and intimacy in distance relationships', Sociological Review 52(2): 180-200.

Holmes, M. (2004b) 'The precariousness of choice in the new sentimental order: A response to Bawin-Legros', Current Sociology, 52(2): 251-7.

Holmes, M. (2010) 'The emotionalization of reflexivity', Sociology, 44(1): 139-54.

Jamieson, L. (1998) Intimacy: Personal relationships in modern societies, Cambridge: Polity.

Jamieson, L. (2004) 'Intimacy, negotiated nonmonogamy and the limits of the couple', in J.

Duncombe, K. Harrison, G. Allan, and D. Marsden (eds) The state of affairs, Mahwah, NJ: Lawrence Erlbaum, 35-57.

Kaufmann, J.-C. (2008) The single woman and the fairytale prince, Cambridge: Polity.

Lampard, R. and Peggs, K. (2007) Identity and repartnering after separation, Basingstoke: Palgrave.

Lauer, S. and Yodanis, C. (2010) 'The deinstitutionalization of marriage revisited: A new institutional approach to marriage', Journal of Family Theory and Review, 2(1): 58-72.

Lesthaeghe, R. (2010) 'The unfolding story of the Second Demographic Transition', Population and Development Review, 36(2): 211-51.

Macvarish, J. (2008) Intimacy in the 21st century: The negotiation of divergent rationalities, Paper presented at the ISA Conference, Barcelona, September. 
National Centre for Social Research [NatCen]. (2005) National Survey of Sexual Attitudes and Lifestyles II, 2000-2001 [computer file], Colchester: UK Data Archive. [SN5223].

Reynolds, J. (2008) The single woman: a discursive investigation, London: Routledge.

Roseneil, S. (2000) 'Queer frameworks and queer tendencies: Towards an understanding of postmodern transformations of sexuality', Sociological Research Online, 5(3), <http://www.socresonline.org.uk/5/3/roseneil.html >

Roseneil, S. (2006) 'On not living with a partner: Unpicking coupledom and cohabitation', Sociological Research Online, 11(3),

<http://www.socresonline.org.uk/11/3/roseneil.html>.

Roseneil, S. and Budgeon, S. (2004) 'Cultures of intimacy and care beyond the family: Personal life and social change in the early twenty-first century', Current Sociology, 52(2): 135-59.

Scott, J. (1998) 'Changing attitudes to sexual morality: a cross-national comparison', Sociology, 32(4): 815-45.

Simpson, R. (2009) Contemporary spinsterhood in Britain, Saarbrücken: VDM Verlag.

Spencer, L. and Pahl, R. (2006) Rethinking friendship, Princeton: Princeton UP.

Trimberger, E.K. (2005) The new single woman, Boston, MA: Beacon Press.

Weeks, J. (2007) The world we have won: The remaking of erotic and intimate life, London: Routledge. 
Table 1: Ideals for the future/current lifestyles (16-44 year-olds)

NATSAL I NATSAL II

(1990)

(1999-2001)

\section{No co-resident partner: ideal sexual lifestyle in five years' time}

Prefer to have no sex activity

$20(0.6)$

$43(0.4)$

No regular partners, but casual partners when

$31(0.9)$

$65(0.5)$

I feel like it

A few regular partners

$28(0.8)$

$92(0.8)$

One regular partner but not living together

Not married, but living with a partner, and with some sex activity outside the partnership

$156 \quad(4.7)$

$730 \quad(6.0)$

$30(0.9)$

$185(1.5)$

Not married, but living with a partner, and no other sex partners

$316(9.5) \quad 1532(12.7)$

Married, with some sex activity outside the marriage

$22(0.7)$

$96 \quad(0.8)$

Married, with no other sex partners

$583(17.5)$

1994 (16.5)

No ideal/None of these/Don't know

64 (1.9)

$150 \quad(1.2)$

Co-resident partner: current relationship type

Married

$1805(54.1) \quad 5097(42.2)$

Cohabiting

$279 \quad(8.4)$

2091 (17.3)

Total

3334

12075

Notes:

- Bracketed values are percentages of the whole sample aged 16-44 for a given survey.

- NATSAL I results have been standardised, ensuring comparability with NATSAL II's age structure. 
Table 2: Ideals for the future/current lifestyles, according to age group

\begin{tabular}{|c|c|c|c|c|c|}
\hline \multirow{4}{*}{$\begin{array}{l}\text { NATSAL I } \\
\text { (1990) }\end{array}$} & \multirow{6}{*}{$\begin{array}{l}\text { Coupledom } \\
\text { LAT } \\
\text { More than } \\
\text { one } \\
\text { partner } \\
\text { Other }\end{array}$} & \multicolumn{4}{|c|}{ Age } \\
\hline & & $16-19$ & $20-24$ & $25-29$ & $30-44$ \\
\hline & & $267(66.9)$ & $413(86.2)$ & $544(93.5)$ & 1758 (93.9) \\
\hline & & $60(15.0)$ & $31 \quad(6.5)$ & $19 \quad(3.3)$ & $47 \quad(2.5)$ \\
\hline & & $45(11.3)$ & $23 \quad(4.8)$ & $10 \quad(1.7)$ & $32 \quad(1.7)$ \\
\hline & & $27 \quad(6.8)$ & $12 \quad(2.5)$ & $9 \quad(1.5)$ & $36 \quad(1.9)$ \\
\hline \multirow{4}{*}{$\begin{array}{l}\text { NATSAL } \\
\text { II } \\
(\mathbf{1 9 9 9 - 2 0 0 1 )}\end{array}$} & Coupledom & $941(64.9)$ & $1490(85.9)$ & 1973 (93.6) & $6310(93.0)$ \\
\hline & LAT & $280(19.3)$ & $116 \quad(6.7)$ & $64 \quad(3.0)$ & $271 \quad(4.0)$ \\
\hline & $\begin{array}{l}\text { More than } \\
\text { one } \\
\text { partner }\end{array}$ & $181(12.5)$ & $102 \quad(5.9)$ & $52 \quad(2.5)$ & $104 \quad(1.5)$ \\
\hline & Other & $47 \quad(3.2)$ & $26 \quad(1.5)$ & $19 \quad(0.9)$ & $101 \quad(1.5)$ \\
\hline
\end{tabular}

Note:

- 'Coupledom' includes married and cohabiting respondents, and others with a sexually exclusive co-resident relationship as their stated ideal. All other categories relate to ideals. 
Table 3: A sexually exclusive, co-resident couple relationship as an ideal situation in five years' time: Odds ratios from a logistic regression

\begin{tabular}{|c|c|c|c|c|}
\hline Explanatory variable & $n$ & O.R. & $p$ & \\
\hline Sex (Reference category=Men) & 3232 & & 0.916 & \\
\hline Female & 2676 & 0.985 & 0.916 & \\
\hline Age (Reference category=16-17) & 923 & & 0.000 & LM \\
\hline $18-19$ & 729 & 1.112 & 0.489 & \\
\hline $20-24$ & 1454 & 2.043 & 0.000 & LM \\
\hline $25-29$ & 989 & 2.788 & 0.000 & LM \\
\hline $30-34$ & 707 & 1.748 & 0.002 & LM \\
\hline $35-39$ & 594 & 1.354 & 0.113 & \\
\hline $40-44$ & 512 & 0.825 & 0.330 & \\
\hline Age*Sex (Interaction) & & & 0.004 & LM \\
\hline Women/18-19 & & 1.988 & 0.003 & $\mathrm{M}$ \\
\hline Women/20-24 & & 1.072 & 0.730 & $\mathrm{M}$ \\
\hline Women/25-29 & & 0.951 & 0.831 & \\
\hline Women/30-34 & & 0.920 & 0.728 & \\
\hline Women/35-39 & & 0.672 & 0.094 & $\mathrm{~L}$ \\
\hline Women/40-44 & & 0.926 & 0.750 & \\
\hline Last sexual relationship (R.C. $=$ Other) & 3695 & & 0.000 & $\mathrm{~L}$ \\
\hline No sexual relationships/partners & 788 & 0.606 & 0.001 & $\mathrm{~L}$ \\
\hline With casual partner & 1044 & 0.700 & 0.000 & LM \\
\hline With (former) cohabiting partner & 344 & 1.520 & 0.010 & $\mathrm{~L}$ \\
\hline Second or later marriage & 37 & 0.553 & 0.100 & \\
\hline Sexual partners in last year (R.C. $=1-2$ ) & 3442 & & 0.000 & LM \\
\hline 0 & 1396 & 0.778 & 0.023 & \\
\hline $3-7$ & 907 & 0.782 & 0.009 & M \\
\hline $8+$ & 163 & 0.434 & 0.000 & LM \\
\hline Same-sex attraction (R.C.=Other) & 5253 & & 0.000 & LM \\
\hline Yes & 655 & 0.620 & 0.000 & LM \\
\hline Parental social class (R.C.=Other) & 3787 & & 0.000 & LM \\
\hline Skilled non-manual/skilled manual & 2121 & 1.305 & 0.000 & LM \\
\hline Occupational class (R.C.=Non-manual) & 2488 & & 0.006 & $\mathrm{~L}$ \\
\hline Other & 3420 & 0.812 & 0.006 & $\mathrm{~L}$ \\
\hline Highest qualification (R.C.=Degree) & 968 & & 0.005 & $\mathrm{~m}$ \\
\hline Other & 4940 & 0.737 & 0.005 & $\mathrm{~m}$ \\
\hline Employment status (R.C.=Other) & 3594 & & 0.000 & LM \\
\hline Full-time education & 1464 & 0.646 & 0.000 & $\mathrm{~L}$ \\
\hline Waiting to take up a job & 38 & 0.372 & 0.007 & $\mathrm{M}$ \\
\hline Unemployed, receiving benefit & 317 & 0.599 & 0.000 & LM \\
\hline Long-term illness/disability & 148 & 0.518 & 0.001 & $\mathrm{~L}$ \\
\hline Looking after family/home & 347 & 0.530 & 0.000 & $\mathrm{~L}$ \\
\hline Has had a child (R.C.=Yes) & 1284 & & 0.001 & $\mathrm{~L}$ \\
\hline No & 4624 & 1.720 & 0.001 & $\mathrm{~L}$ \\
\hline Importance: children (R.C.=Very) & 1395 & & 0.833 & \\
\hline Other & 4513 & 0.971 & 0.833 & \\
\hline Has had child*Importance: children (Interaction) & & & 0.032 & $\mathrm{~L}$ \\
\hline No/Other & & 0.696 & 0.032 & $\mathrm{~L}$ \\
\hline Region (R.C.=South and East of Britain) & 1662 & & 0.001 & LM \\
\hline London & 976 & 0.720 & 0.002 & $\mathrm{M}$ \\
\hline North and West & 3270 & 0.779 & 0.001 & LM \\
\hline Has always lived locally (R.C.=Yes) & 3023 & & 0.005 & $\mathrm{~L}$ \\
\hline Other & 2885 & 1.208 & 0.005 & $\mathrm{~L}$ \\
\hline
\end{tabular}


Table 3: (continued)

\begin{tabular}{|c|c|c|c|c|}
\hline Explanatory variable & $n$ & O.R. & $p$ & \\
\hline Housing tenure (R.C.=Other) & 2208 & & 0.000 & LM \\
\hline Owner occupation & 3297 & 1.219 & 0.009 & $\mathrm{M}$ \\
\hline Rented (Housing Association) & 325 & 1.504 & 0.005 & $\mathrm{Lm}$ \\
\hline Tied to job & 63 & 4.141 & 0.004 & $\mathrm{~L}$ \\
\hline Rent-free & 15 & 0.245 & 0.013 & M \\
\hline Type of dwelling (R.C.=Detached house) & 948 & & 0.001 & LM \\
\hline Other & 4960 & 1.353 & 0.001 & LM \\
\hline Ethnic group (R.C.=Other) & 5856 & & 0.002 & $\mathrm{M}$ \\
\hline Bangladeshi & 16 & 12.274 & 0.028 & 1 \\
\hline Chinese & 36 & 0.357 & 0.005 & M \\
\hline Importance of religion/beliefs (R.C.=Very) & 569 & & 0.000 & LM \\
\hline Other & 3214 & 0.745 & 0.016 & LM \\
\hline Not at all & 2125 & 0.540 & 0.000 & LM \\
\hline Importance: adequate income (R.C.=Very) & 891 & & 0.040 & $\mathrm{~m}$ \\
\hline Other & 5017 & 1.201 & 0.040 & $\mathrm{~m}$ \\
\hline Importance: fidelity (R.C.=Very) & 5427 & & 0.000 & M \\
\hline Quite & 439 & 0.723 & 0.005 & M \\
\hline Other & 42 & 0.292 & 0.001 & M \\
\hline Importance: sharing chores (R.C.=Very) & 1716 & & 0.019 & \\
\hline Other & 4192 & 1.184 & 0.019 & \\
\hline Importance: mutual respect (R.C.=Other) & 5116 & & 0.001 & $\mathrm{~L}$ \\
\hline Quite & 755 & 0.730 & 0.001 & $\mathrm{~L}$ \\
\hline Not very/Not at all & 37 & 1.904 & 0.108 & 1 \\
\hline Wrong: adultery (R.C.=Always) & 3277 & & 0.000 & LM \\
\hline Mostly & 1804 & 0.812 & 0.006 & LM \\
\hline Other & 827 & 0.587 & 0.000 & LM \\
\hline Wrong: unfaithful (R.C.=Always/mostly/sometimes) & 5394 & & 0.008 & M \\
\hline Other & 514 & 0.751 & 0.008 & M \\
\hline Wrong: one night stands (R.C.= Other) & 4694 & & 0.007 & M \\
\hline Not wrong at all & 1214 & 0.801 & 0.007 & M \\
\hline Wrong: abortion (R.C.=Other) & 4906 & & 0.000 & LM \\
\hline Not wrong at all & 1002 & 0.696 & 0.000 & LM \\
\hline Wrong: homosexual relations: men (R.C.=Other) & 4349 & & 0.012 & M \\
\hline Always & 1559 & 0.822 & 0.012 & M \\
\hline Sex most important part of marriage (R.C. $=$ Other) & 2107 & & 0.000 & LM \\
\hline Disagree/Strongly disagree & 3801 & 1.314 & 0.000 & LM \\
\hline
\end{tabular}

Notes:

- $\quad n=$ sub-sample size; O.R.=odds ratio.

- Model chi-square=909.1 (57 d.f.); -2LL=6081.7; Pseudo- $r^{2}$ (Cox \& Snell)=0.143; bold $p$ values correspond to variables' overall significance.

- R.C.=Reference category; 'Other' categories sometimes contain a few missing values.

- $\mathrm{L}$ or M indicates a significant effect $(p<0.05)$ in a more specific model comparing either LAT $[\mathrm{L}]$ or a multiple partner lifestyle $[\mathrm{M}]$ with a sexually exclusive, co-resident couple relationship as an ideal; similarly, 1 or $m$ indicates an effect within such a model which, while non-significant, is greater in magnitude than the (significant) effect within the broader model.

- The 'Importance' variables relate to the perceived importance of characteristics for long-term relationships/marriages. The 'Wrong: unfaithful' variable relates to unfaithfulness to 'regular partners'. The 'Importance' questions' possible answers were: 'Very', 'Quite', 'Not very', 'Not at all' and 'Don't know'. The 'Wrong' questions' possible answers were: 'Always', 'Mostly', 'Sometimes', 'Rarely', 'Not at all' and 'Depends/Don't know'. 